\title{
Thoracoscopic anterior stabilization for thoracolumbar fractures in patients without spinal cord injury: quality of life and long-term results
}

\author{
Arjen J. Smits ${ }^{1}$ (D) Arwin Noor $^{1} \cdot$ Fred C. Bakker $^{1} \cdot$ Jaap Deunk ${ }^{1} \cdot$ Frank W. Bloemers $^{1}$ \\ Received: 15 May 2017 / Revised: 11 March 2018 / Accepted: 27 March 2018 / Published online: 3 April 2018 \\ (c) The Author(s) 2018
}

\begin{abstract}
Purpose To determine the health-related quality of life (QOL), safety and radiologic parameters after thoracoscopic treatment of traumatic thoracolumbar fractures using a distractible cage in patients without spinal cord injury (SCI).

Methods Retrospective cohort study of patients treated between 2004 and 2012 in a university level-one trauma center. Patient and treatment characteristics were collected from the hospital information system. All available radiographic material was assessed for fracture characteristics and Cobb angle at consecutive times. Patients completed the SF-36 and EQ-5D QOL questionnaires at follow-up.

Results 105 patients were treated with a distractible cage, which was performed thoracoscopically in 86 cases, including 16 patients with SCI. Of 70 eligible patients, 46 were available for follow-up and completed the questionnaires at median 49 months after surgery. QOL was lower on most domains compared to the general population. Compared to patients who underwent solely posterior fixation for less severe fractures, QOL did not differ significantly. The complication rate was low $(10 \%)$ with one re-operation. Mean loss of correction was $6.8^{\circ}$ and bony fusion on CT scan was present in $98 \%$ of patients. Maintenance of kyphosis correction was significantly better for two segments anterior fixation compared to one segment.

Conclusions Thoracoscopic anterior stabilization leads to a high percentage of bony fusion in highly unstable thoracic and thoracolumbar fractures with limited post-operative loss of correction and no hardware failure. QOL of these patients does not return to normal population values but is comparable to that of patients with less severe fractures treated with solely posterior instrumentation.
\end{abstract}

Graphical abstract These slides can be retrieved under Electronic Supplementary Material.
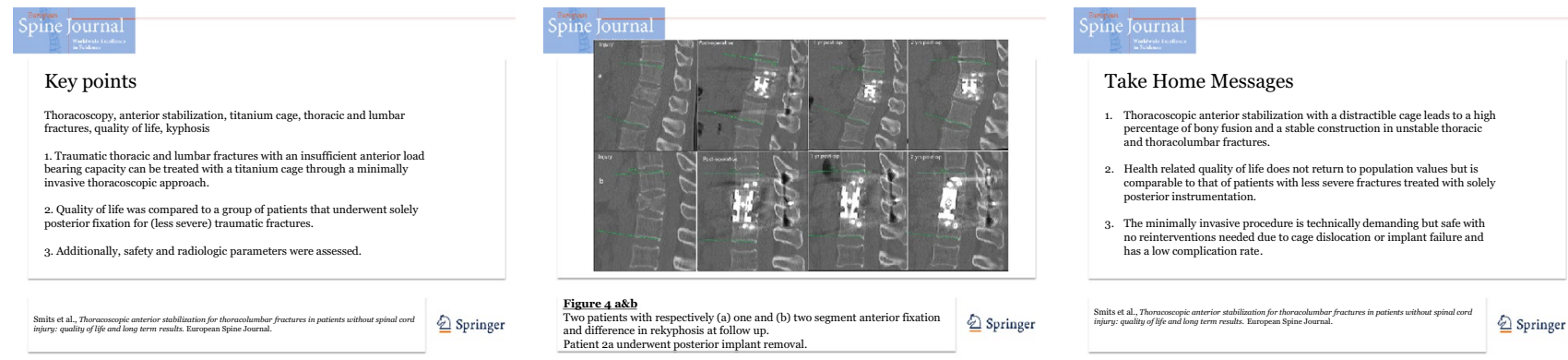

Keywords Thoracoscopy $\cdot$ Expandable cage $\cdot$ Quality of life $\cdot$ Antero-posterior instrumentation $\cdot$ Spine fracture

Electronic supplementary material The online version of this article (https://doi.org/10.1007/s00586-018-5571-7) contains supplementary material, which is available to authorized users.

Extended author information available on the last page of the article 


\section{Introduction}

A growing number of spine surgeons advocate the reconstruction of the anterior spinal column in cases with insufficient anterior load bearing capacity [1-7]. Additional anterior stabilization provides stability to the anterior column, thereby preventing loss of correction and posterior implant failure [7, 8]. Compared to bone strut grafts, a distractible titanium cage is nowadays considered a safe and effective treatment option. Advantages are in situ expansion, maximization of endplate contact with vertebral bodies and the possibility of minimally invasive implanting [2-4]. With the use of titanium cages, the disadvantages of autologous bone struts are prevented such as operating time, donor site morbidity, non-union and fracture of the strut graft [9].

The traditional anterior approach to treat thoracic and high lumbar fractures is invasive and induces secondary damage with thoracotomy or thoracophrenicolaparotomy-related complications up to $26 \%$ [4]. An alternative approach is the mini-open thoracoscopic-assisted technique [7, 10-12]. And although satisfactory results were obtained, the minimally invasive video-assisted thoracoscopy (VATS) technique provides advantages such as smaller incisions, no need for rib resection, excellent visualization and minimal surgical chest wall injury [13]. If stabilization with a cage is performed using VATS, a stable construction can be provided through a minimally invasive procedure to reduce surgical damage [13-17].

While the treatment of thoracic and thoracolumbar fractures is often evaluated in terms of radiological and functional outcomes [2, 18], it has been shown that these often do not correlate $[3,19]$. This elucidates the importance of health-related quality of life (hr-QOL) after treatment of these fractures. Reporting patient-reported outcome measurements (PROMs) provides new insights into treatment evaluation. While several tools to measure PROMs are readily available, there is no literature that reports QOL after minimally invasive antero-posterior treatment of thoracic and thoracolumbar fractures using a cage. Studies that do report results after anterior stabilization with a cage include patients treated with an open approach [4, 20], mini-open approach [7] or do not report QOL [7, 15, 20].

To our knowledge, this is the first study on the mid- to longterm quality of life after thoracic and thoracolumbar fractures treated with an expandable cage through a thoracoscopic approach. In addition, radiological parameters and safety of the technique are addressed.

\section{Materials and methods}

\section{Patients}

The study was performed retrospectively with additional QOL data collection. The study was reported according to the STROBE-statement for observational studies. Between 2004 and 2012, 105 consecutive patients were treated with anterior stabilization using an anterior cage for traumatic thoracic and thoracolumbar fractures, in most cases after primary posterior stabilization. These patients consisted of primary presentations at our university level 1 trauma center and referrals from regional hospitals. In 86 cases, anterior stabilization was performed thoracoscopically. Patients without sufficient knowledge of the Dutch language, not living in the Netherlands, with osteoporotic/ pathological fractures and/or neurologic injury were excluded from the study. Patients were followed up on a regular basis the first year and at least once the following years until bony fusion around the cage was complete.

\section{Data collection and clinical follow-up}

Patient and injury characteristics were collected from the trauma registration and hospital information system. These included age, sex, mechanism of injury, medical history, primary presentation or referral, AO-classification, load sharing classification (LSC) [21], neurologic injury, other injuries, injury severity score (ISS), surgical treatment, complications and duration of admission. Radiographic parameters such as fracture characteristics, kyphosis (Cobb angle), LSC and bony fusion were assessed by two separate spine specialized trauma surgeons. This was primarily done on available CT scans and if not available on MRI, conventional radiographs and perioperative reports, at injury and follow-up. Quality of life was assessed at follow-up using two validated health-related QOL questionnaires, the EuroQuol 3 dimensions (EQ-5D-3L) and the Short Form 36 (SF-36) after at least 1 year of followup. QOL scores were compared to scores of the general Dutch population [22, 23] and due to the lack of reported QOL scores after anterior treatment in the literature, to a population of patients with traumatic fractures treated with solely posterior fixation and subsequent implant removal treated in the same hospital [24]. The study was performed under approval of the institutional medical ethical committee (METc VUmc). 


\section{Indication for anterior stabilization and surgical technique}

All patients with unstable thoracic and thoracolumbar fractures were primarily treated with posterior fixation. In accordance with existing literature, fractures with an LSC of $\geq 7$ were indicated for additional anterior stabilization [21]. Fractures with an LSC $<7$ could still be indicated for additional anterior stabilization in case of persistent deformity after posterior fixation, combined with severe comminution or a Cobb angle $>30^{\circ}$, a depression $>50 \%$ or a pincer type fracture. Posterior fixation consisted of pedicle screws and rods (Universal Spine System, Depuy Synthes, Zuchwil, Switzerland) which were inserted through an open approach, without posterior fusion. After posterior fixation, the anterior procedure is planned as an elective procedure after the patient is recovered and fracture stability is re-evaluated. Anterior stabilization was performed thoracoscopically using an expendable cage, combined with thoracoscopic anterolateral plating. The trans-thoracic approach is used up to L2 fractures, for which the crus of the diaphragm is detached and the diaphragm pushed caudally. Thoracoscopic anterior fixation was done in a secondary elective procedure with the patient in lateral decubitus position. An expandable titanium cage (Obelisc, Ulrich medical, Ulm, Germany) was thoracoscopically implanted after partial corpectomy and disc removal. Corpectomy bone was applied around the cage, in most cases mixed with demineralized bone matrix (DBX, Depuy Synthes, Zuchwil, Switzerland) to stimulate vertebral fusion. Additionally, thoracoscopic anterolateral plating (MACS-TL, Braun, Melsungen, Germany) was performed to improve stability $[25,26]$ and stimulate bony fusion [27]. In most patients, the plate connected the vertebra above and below the fractured vertebra (2 segment fixation). Dependent on the surgeon's judgement of intact vertebra and fracture morphology, in some patients the cage and plate connected the lower intact segment of the fractured vertebra and the vertebra above (1 segment fixation). In one patient, three segments were connected due to two adjacent severely fractured vertebra. Post-operative care consisted of $24 \mathrm{~h}$ bed rest, analgesics, thrombosis prophylaxis while clinical and mobilization with an orthosis for 6-12 weeks. For specific reasons such as polytrauma, the treating surgeon could deviate from this protocol. All patients received post-operative physiotherapy. Removal of posterior implants was done after approximately 1 year based on implant-related symptoms or to improve mobility at the not anteriorly fixated segment if only one anterior segment was fixated. In cases with longer posterior fixation ( $\geq 3$ segments), removal was preferred to improve mobility but depended on fusion and consolidation of any additional fractures.

\section{Statistics}

Continuous data with normal distribution are reported as means with standard deviation (SD); skewed data are reported as median with interquartile range (IQR). Categorical data are reported as frequencies with ratios. To compare means with a normal distribution between two groups, a $t$ test was used and ANOVA for three groups or more. Categorical variables were analyzed using Fisher's exact test. Linear regression was used to test possible correlations and to compare means at different moments for different groups. Multiple regression analysis was used to test for confounding and effect modification (of multiple fractures, fracture type, anterior segments fixated and ISS). The SF-36 does not follow a normal distribution [28] but in concordance with previous literature [22] and to compare the values to those of a general population, means with SD were used. Statistical significance was defined as $p<0.05$. Analyses were performed using IBM SPSS 22.0.

\section{Results}

\section{Demographics}

The 86 patients that were treated with a distractible cage through a minimally invasive thoracoscopic approach had fractures ranging from T6 to L2. Sixteen of them had spinal cord injury and were not eligible for this study. Forty-six (66\%) of the remaining 70 eligible patients met the inclusion criteria and were available for follow-up. They filled in the QOL questionnaires and were further analyzed and described. The questionnaires were filled in at a median of 49 months (IQR 25-82) after anterior surgery. Also all questionnaires were filled in after (if any) posterior implant removal. The mean age at trauma was 40 years (range 16-62), the median ISS score was 9 (IQR 9-13) and eight patients had an ISS $\geq 16$. Of all fractures (T6-L2), 74\% was located between $\mathrm{T} 11$ and L1, and $9 \%$ of fractures were located at L2. Most fractures consisted of AO type A4 $(n=31 ; 67 \%)$ and $41 \%$ of the patients had an additional AO type $\mathrm{B}(n=18)$ or $\mathrm{C}(n=1)$ injury. Thirty $(65 \%)$ patients had a load sharing classification of $\geq 7$. All but two patients had initial posterior stabilization; most patients (82\%) had two segment dorsal stabilization. Anterior stabilization consisted of two segments in 27 (59\%) patients. In two patients, it was decided that fracture reduction and stabilization could be performed sufficiently with a solely anterior approach. The anterior procedure took mean 213.9 \pm 74.6 min (range 108-435 min) and the median blood loss was $600 \mathrm{~mL}$ (IQR 275-1100). Operative time and blood loss decreased significantly over time from 2004 to $2013\left(R^{2}=0.202 ; p<0.01\right.$ and $R^{2}=0.18 ; p<0.01$, respectively). Mean hospital stay 
after anterior stabilization was $8 \pm 5$ days for patients with an ISS $<16$ and mean $20 \pm 16$ days for polytrauma patients (ISS $\geq 16$ ). Mean duration between posterior and anterior stabilization was $10 \pm 7$ days (range $0-30$ ). There was one

Table 1 Patient characteristics

\begin{tabular}{|c|c|}
\hline$n$ & 46 \\
\hline Sex M:F & $26: 20(56: 44 \%)$ \\
\hline Transfer from other hospital & $22(48 \%)$ \\
\hline Known psychiatric history & $6(13 \%)$ \\
\hline \multicolumn{2}{|l|}{ Mechanism of injury } \\
\hline Fall/jump off height & $18(39 \%)$ \\
\hline Traffic accident & $15(33 \%)$ \\
\hline Fall from stairs & $5(11 \%)$ \\
\hline Sports accident & $3(7 \%)$ \\
\hline Fall off horse & $2(4 \%)$ \\
\hline Object on back/entrapment & $2(4 \%)$ \\
\hline Conventional fall & $1(2 \%)$ \\
\hline ISS (median, IQR) & $9(9-13)$ \\
\hline \multicolumn{2}{|l|}{ Load sharing classification $^{\mathrm{a}}$} \\
\hline $4-6$ & $16(35 \%)$ \\
\hline $7-9$ & $30(65 \%)$ \\
\hline \multicolumn{2}{|l|}{ Level of injury } \\
\hline Th6-Th9 & $8(17 \%)$ \\
\hline Th11-L1 & $34(74 \%)$ \\
\hline $\mathrm{L} 2$ & $4(9 \%)$ \\
\hline \multicolumn{2}{|l|}{ AO morphology ${ }^{b}$} \\
\hline A2 & $1(2 \%)$ \\
\hline A3 & $14(31 \%)$ \\
\hline A4 & $31(67 \%)$ \\
\hline B2 & $18(39 \%)$ \\
\hline $\mathrm{C}$ & $1(2 \%)$ \\
\hline $\begin{array}{l}\text { Patients with multiple vertebral fractures (type- } \\
\text { A/B/C) }\end{array}$ & $18(39 \%)$ \\
\hline \multicolumn{2}{|l|}{ Posterior segments immobilized $^{c}$} \\
\hline 2 & $36(82 \%)$ \\
\hline 3 & $6(13 \%)$ \\
\hline 4 & $2(5 \%)$ \\
\hline \multicolumn{2}{|l|}{ Anterior segments immobilized ${ }^{c}$} \\
\hline 1 & $18(39 \%)$ \\
\hline 2 & $27(59 \%)$ \\
\hline 3 & $1(2 \%)$ \\
\hline \multicolumn{2}{|l|}{ Removal of posterior implant } \\
\hline Yes & $23(52 \%)$ \\
\hline No & $21(48 \%)$ \\
\hline
\end{tabular}

${ }^{\mathrm{a}}$ For four patients, it was not possible to calculate the LSC because these patients were transferred from another hospital and initial radiographs were no longer available

${ }^{\mathrm{b}} \mathrm{AO}$ morphology subjects overlap total $\mathrm{n}$ because all B and $\mathrm{C}$ type injuries were associated with an A type fracture

${ }^{\mathrm{c}} 1$ segment corresponds with the space between two vertebra, see also Fig. 4 exception of 3.5 months between surgeries; in this case, late anterior stabilization was decided because of increasing pain and imminent loss of reduction after solely posterior stabilization. The posterior implant was removed in 21 patients after median 11 months (IQR 11-15). Baseline characteristics are further specified in Table 1.

\section{Quality of life}

Stratified QOL scores for injury severity (ISS $<$ and $\geq 16$ ) are reported in Table 2 and Figs. 1, 2. The EQ-5D and SF-36 scores do not differ from the stratified scores of a cohort of patients that underwent only posterior fixation for traumatic thoracic and thoracolumbar fractures treated in the same hospital and reported in the literature [24]. This is a group of patients with comparable demographics; baseline characteristics of these patients are shown in Table 3. An important, but expected, difference is, however, that the current population shows significantly more A4 type fractures than A3 type fractures $\left(X^{2}\right.$ test; $\left.p<0.01\right)$.

When comparing the SF-36 scores to the general population [22], the group with an ISS $<16$ showed significantly lower QOL on the domains physical function $(p<0.05)$, bodily pain and vitality $(p<0.01)$. The group with an ISS $\geq 16$ reported only lower QOL on the domain role physical $(p<0.05)$. This group, however, consisted only of eight patients. The other domains did not show statistical differences.

On the EQ-5D, the group with an ISS $<16$ showed lower QOL compared to the general population [23] on the domains mobility, usual activity, pain and anxiety $(p<0.01)$. The overall index score (mean difference $-0.10 ; p<0.01$ ) and EQ-5D VAS score (mean difference $-6.7 ; p<0.01$ ) were significantly lower. For the group with an ISS $\geq 16$

Table 2 Stratified quality of life scores (SF36 and EQ5D) of the study population

\begin{tabular}{lll}
\hline SF36 domain & ISS $<16(n=38)$ & ISS $\geq 16(n=8)$ \\
\hline Physical function & $77 \pm 17$ & $63 \pm 39$ \\
Role physical & $63 \pm 39$ & $41 \pm 42$ \\
Bodily pain & $63 \pm 23$ & $63 \pm 27$ \\
General health & $69 \pm 22$ & $59 \pm 24$ \\
Vitality & $60 \pm 21$ & $62 \pm 24$ \\
Social functioning & $73 \pm 28$ & $66 \pm 29$ \\
Role emotional & $71 \pm 40$ & $67 \pm 47$ \\
Mental health & $71 \pm 22$ & $82 \pm 12$ \\
Physical component score & $47 \pm 9$ & $40 \pm 14$ \\
Mental component score & $46 \pm 13$ & $49 \pm 7$ \\
EQ5D & & \\
EQ5D-VAS & $75 \pm 15$ & $75 \pm 18$ \\
EQ5D-index & $0.81 \pm 0.13$ & $0.75 \pm 0.23$ \\
\hline
\end{tabular}




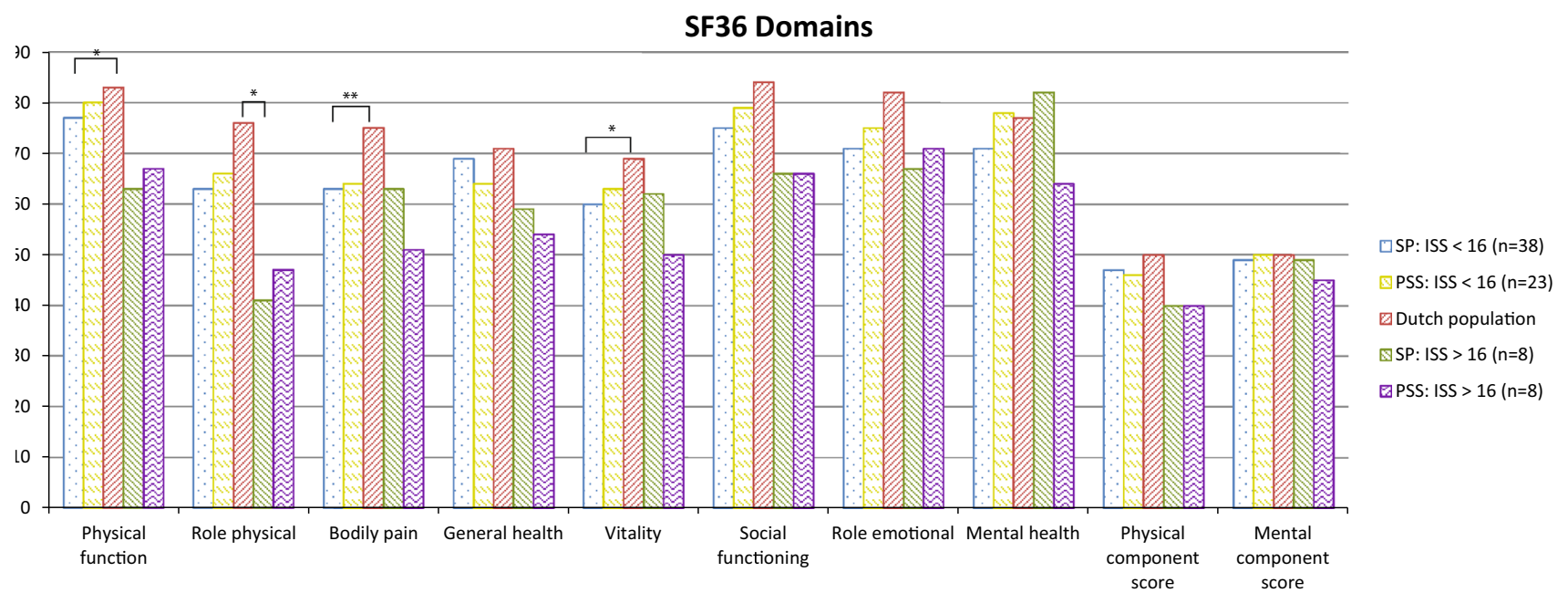

Fig. 1 Mean results of SF-36 domains of the study population, compared to patients with solely posterior short segment fixation [24] (PSS) and the general population. $S P$ study population, $P S S$ posterior short segment fixation. ${ }^{*} p<0.05 ; * * p<0.01$

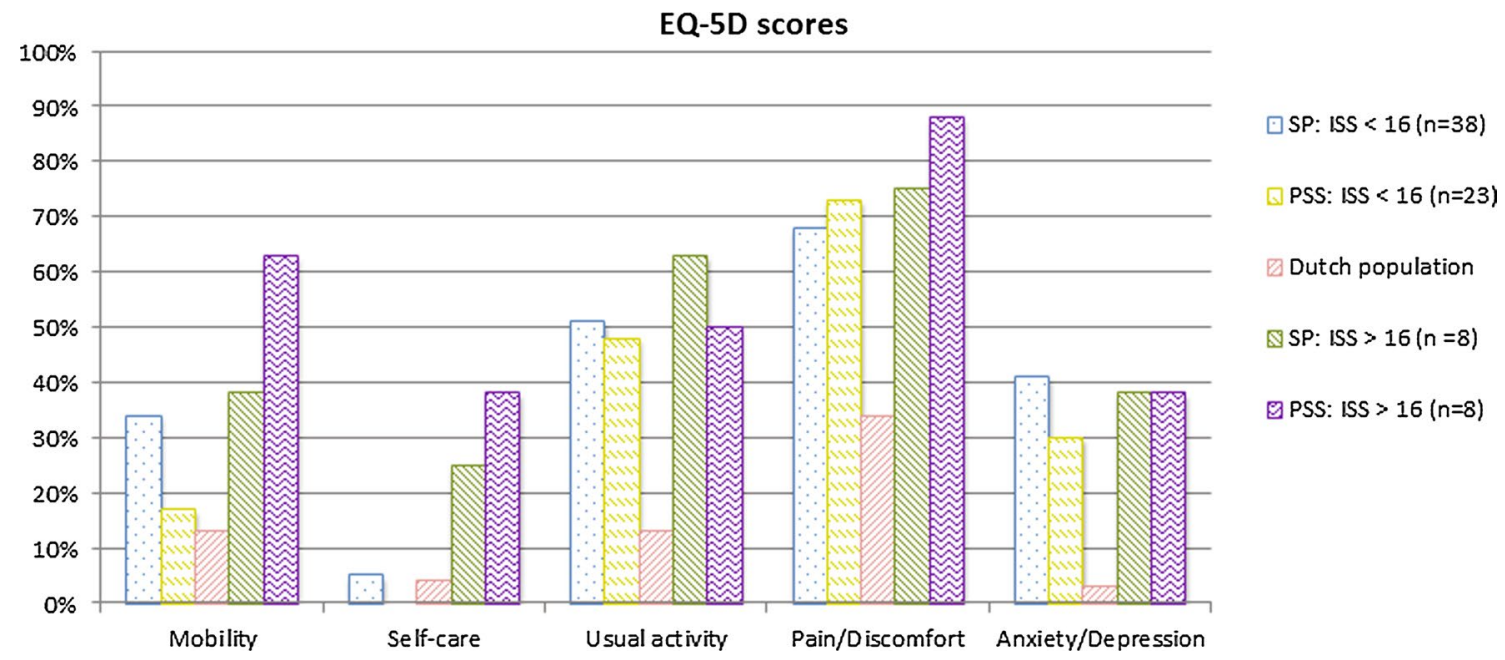

Fig. 2 EQ5D scores as ratios of patients that reported problems on the respective domains, compared to patients with solely posterior short segment fixation [24] and the general population. PSS study

$(n=8)$, lower QOL was reported on all domains $(p<0.01)$. The difference in overall index score (mean difference $-0.16 ; p<0.09$ ) and EQ-5D VAS score (mean difference $-6.4 ; p=0.3$ ) did not show statistical significance. Fourteen patients filled in the SF36 and EQ-5D twice at consecutive times with median time between questionnaires 13 months (IQR 12-23). Outcomes did not significantly change over time.

No correlations were found between the amount of correction loss after surgery and the QOL scores on all domains of the SF36 and EQ5D. Summary scores with regression coefficients are reported in Table 4. In addition, no correlations were found between QOL and mono- or bisegmental with fractures treated with solely posterior short segment fixation, $S P$ study population. ${ }^{*} p<0.01$

anterior fixation, fracture level (thoracic vs thoracolumbar), fracture morphology, posterior implant removal or complications (see Table 4).

\section{Complications}

Post-operative complications (Table 5) were present in five of the 46 patients (10\%) of which one (2\%) required a thoracotomy due to a persistent haemothorax with signs of infection despite tube thoracostomy. The patients with pneumonia and spondylodiscitis (on a different level than the operated level) were successfully treated with antibiotics. One patient had post-operatively $15^{\circ}$ cage dislocation, 
Table 3 Characteristics of reference group with only posterior fixation

\begin{tabular}{ll}
\hline$N$ & 31 \\
Sex (M:F) & $20: 11(65: 35 \%)$ \\
Age (mean, SD) & $41 \pm 15$ \\
ISS (median, IQR) & $9.0(4-16)$ \\
AO morphology & \\
A1 & $2(7 \%)$ \\
A2 & $1(3 \%)$ \\
A3 & $22(71 \%)$ \\
A4 & $6(19 \%)$ \\
B1-3 & $13(42 \%)$ \\
C & $3(10 \%)$ \\
Fracture level & \\
T5-T8 & \\
T11-L1 & $4(13 \%)$ \\
L2-L4 & $20(65 \%)$ \\
Multiple fractures & $7(23 \%)$ \\
Yes & \\
No & $12(61 \%)$ \\
Dorsal segments fixated & $19(39 \%)$ \\
1 & \\
2 & $1(3 \%)$ \\
3 & $24(77 \%)$ \\
$4-6$ & $2(7 \%)$ \\
Complications & $4(14 \%)$ \\
\hline
\end{tabular}

${ }^{\mathrm{a}} \mathrm{AO}$ morphology subjects may overlap total $\mathrm{n}$ because most $\mathrm{B}$ and $\mathrm{C}$ type injuries are associated with an A type fracture

but this remained stable during follow-up. No patients needed a re-intervention due to cage dislocation or implant failure.

\section{Radiologic parameters}

While post-operatively there was significant kyphosis correction of $-7.5^{\circ}(\mathrm{CI}-9.6-5.3 ; p<0.01)$, a correction loss of $6.8^{\circ}$ (CI $5.0-8.8 ; p<0.01$ ) occurred in consecutive years. Patients with two segment anterior fixation had significantly less correction loss from post-operative to final follow-up compared to patients with only one segment anterior fixation (mean difference corrected for different post-operative values $-4,7^{\circ}$; CI -8.1 to $-1.3 ; p<0.01$ ), Figs. 3,4 and Table 6. Multiple fractures and AO-fracture classification did not confound or modify the effect of this relation. Posterior implant removal was not equally divided among groups with one and two segment anterior fixation; implants were removed in $14(82 \%)$ and $4(21 \%)$ patients, respectively. This led to very small skewed remaining groups that did not allow statistical testing. On CT scan at follow-up, bony fusion of the vertebrae was present in $98 \%$ of patients.

\section{Discussion}

In this study of patients with unstable thoracic and thoracolumbar fractures treated with dorsal stabilization and subsequent thoracoscopic implantation of an expandable cage, we found a bony fusion in almost all cases with limited loss of correction and no implant failure. The healthrelated QOL of these patients after thoracoscopic anterior stabilization is not worse compared to patients with less severe fractures treated only with posterior fixation. Two-segment anterior fixation was found to be superior in maintaining kyphosis correction compared to one segment.

\section{Quality of life}

The spine is involved in nearly all movements of the human musculoskeletal system. Therefore, it is not surprising that patients after a thoracic or thoracolumbar fracture that required both posterior and anterior stabilization do not regain the same QOL as compared to a general population $[29,30]$. This is in correspondence with the existing literature on QOL in trauma patients, in which traumatically injured patients [31] and especially severely injured patients (ISS $\geq 16$ ) $[32,33]$ do not regain general population values. Furthermore, on some domains QOL is not fully decreased and comes back to population values. This has been reported before in a study that thoracoscopically treated patients with bone grafts, although the use of bone grafts in their study led to a high rate of donor site problems [34].

Some discrepancy exists between our results measured on the EQ-5D and SF36. While scores on practically all EQ-5D domains are lower compared to the general population, only a minority of domains is lowered on the SF36 (mainly physical domains). This could be due to subtle differences and while the SF36 allows for detailed scores (0-100), the EQ5D scores are dichotomous (problems vs no problems). Another explanation is the stratification of groups. Because QOL is very likely influenced by multiple injuries, scores are stratified for ISS. This, however, results in a small remaining group with an ISS $\geq 16$ $(n=8)$. Although no statistical differences were found between groups with an ISS $<$ and $\geq 16$, large differences are reported on some domains. This is probably because the group with an ISS $\geq 16$ is not of sufficient size to show statistical difference.

Despite the fact that fractures in the population with additional anterior stabilization were more severe, QOL was not worse compared to the population with less severe fractures that required solely posterior fixation [24]. The patients in the current study mainly presented 
Table 4 Correlation of QOL with fracture, treatment and radiological parameters

\begin{tabular}{lllllllll}
\hline & SF36 PCS & $p$ & SF36 MCS & $p$ & EQ5D index & P & EQ5D VAS & $p$ \\
\hline CA injury & B: $-0.063^{\mathrm{a}}$ & 0.75 & B: $-0.074^{\mathrm{a}}$ & 0.76 & $\mathrm{~B}: 0.00047^{\mathrm{a}}$ & 0.88 & $\mathrm{~B}:-0.12^{\mathrm{a}}$ & 0.68 \\
CA final follow-up & $\mathrm{B}:-0.076^{\mathrm{a}}$ & 0.67 & $\mathrm{~B}:-0.024^{\mathrm{a}}$ & 0.92 & $\mathrm{~B}:-0.001^{\mathrm{a}}$ & 0.81 & $\mathrm{~B}: 0.019^{\mathrm{a}}$ & 0.95 \\
CA post-op to FFU & $\mathrm{B}:-0.023^{\mathrm{a}}$ & 0.95 & $\mathrm{~B}:-0.40^{\mathrm{a}}$ & 0.40 & $\mathrm{~B}:-0.001^{\mathrm{a}}$ & 0.87 & $\mathrm{~B}:-0.29^{\mathrm{a}}$ & 0.61 \\
Fracture level & & & & & & & & \\
T6-T10 & $46.86 \pm 15$ & $0.82^{\circ}$ & $46.57 \pm 12$ & $0.96^{\circ}$ & $0.77 \pm 0.12$ & $0.59^{\circ}$ & $78.38 \pm 17$ & $0.55^{\circ}$ \\
T11-L2 & $45.39 \pm 9$ & & $46.33 \pm 13$ & & $0.80 \pm 0.16$ & & $74.68 \pm 15$ & \\
AO morphology & & & & & & & & \\
A3 & $47.15 \pm 11$ & $0.58^{\circ}$ & $46.92 \pm 14$ & $0.95^{\circ}$ & $0.82 \pm 0.19$ & $0.71^{\circ}$ & $77.29 \pm 20$ & $0.58^{\circ}$ \\
A4 & $45.24 \pm 10$ & & $46.66 \pm 12$ & & $0.80 \pm 0.14$ & & $74.45 \pm 14$ & \\
A3 \& A4 & $45.80 \pm 10$ & & $45.28 \pm 12$ & & $0.79 \pm 0.14$ & & $74.85 \pm 13$ & \\
B2 & $46.06 \pm 11$ & $0.94^{\circ}$ & $47.53 \pm 14$ & $0.58^{\circ}$ & $0.81 \pm 0.18$ & $0.76^{\circ}$ & $76.56 \pm 19$ & $0.73^{\circ}$ \\
Ant. segments & & & & & & & & \\
1 & $48.50 \pm 10$ & $0.13^{\circ}$ & $46.39 \pm 12$ & $0.97^{\circ}$ & $0.83 \pm 0.19$ & $0.38^{\circ}$ & $78.83 \pm 11$ & $0.17^{\circ}$ \\
2 & $43.63 \pm 10$ & & $46.25 \pm 13$ & & $0.78 \pm 0.12$ & & $72.81 \pm 18$ & \\
PIR & & & & & & & & \\
Yes & 45.91 & $0.89^{\circ}$ & 47.45 & $0.55^{\circ}$ & 0.83 & $0.47^{\circ}$ & 76.00 & $0.90^{\circ}$ \\
No & 46.33 & & 44.94 & & 0.79 & & 75.38 & \\
Complications & & & & & & & & \\
No $(n=38)$ & $45.95 \pm 10$ & $0.57^{\circ}$ & $45.47 \pm 13$ & $0.20^{\circ}$ & $0.81 \pm 0.14$ & $0.44^{\circ}$ & $75.05 \pm 16$ & $0.73^{\circ}$ \\
Yes $(n=5)$ & $43.20 \pm 11$ & & $53.20 \pm 8$ & & $0.75 \pm 0.26$ & & $77.60 \pm 9$ & \\
\hline
\end{tabular}

$C A$ Cobb angle, post-op post-operative, $F F U$ final follow-up, $P I R$ posterior implant removal

${ }^{\circ}$ Independent $t$ test

*Statistical significant difference $(p<0.05)$

${ }^{a}$ Linear regression analysis (regression coefficient $(B)$ and corresponding $p$ value)
Table 5 Complications

\begin{tabular}{ll}
\hline Complications & \\
\hline Pneumonia & $1(2 \%)$ \\
Ileus & $1(2 \%)$ \\
Spondylodiscitis (different level) & $1(2 \%)$ \\
Cage dislocation & $1(2 \%)$ \\
Persisting haemothorax (re-thoracotomy) & $1(2 \%)$ \\
Total & $5(10 \%)$ \\
\hline
\end{tabular}

with comminuted type A4 fractures with an LCS of $>7$, resulting in an unstable anterior column. Literature has shown that if these fractures are treated with solely posterior instrumentation, they are at risk of fracture collapse, re-kyphosis and posterior instrumentation failure up to $40 \%$ [6], due to an unstable anterior column [1, 6, 35, 36]. Although a correlation between kyphosis and QOL has not been shown in the literature, a relation with functional outcomes has been reported [37]. This loss of functional outcome because of re-kyphosis due to posterior implant failure and secondary collapse could be prevented by anterior stabilization. Furthermore, if this is performed minimally invasive, the secondary morbidity of the open approach can be avoided. However, this conclusion cannot be drawn solely based on this retrospective study. Only a prospective randomized trial with long-term follow-up could lead to such a conclusion.

\section{Radiologic parameters}

Previous studies already reported that after anterior stabilization using a cage, a loss of correction of $3^{\circ}-6^{\circ}$ might occur during follow-up $[3,4,15,29]$. We report a mean correction loss of $6.8^{\circ}$, which is comparable. Three to 6,8 degrees of radiographic loss of correction are unlikely to be clinically relevant, since only a severe kyphotic deformity of over $30^{\circ}$ is reported to be associated with increased back pain [38]. Moreover, as in the previous literature [34], we could not find a correlation between the loss of correction and QOL. Therefore, we think that a loss of correction of $6.8^{\circ}$ during follow-up is not clinically relevant.

Interestingly, our study shows that the amount of vertebrae connected with anterior fixation has a significant influence on amount of correction loss. The group with two-segment fixation maintains $4.7^{\circ}$ more kyphosis correction from post-operative to final follow-up compared to the group with one segment fixation (Table 6, Fig. 3). One segment anterior fixation was only done if one endplate of the fractured vertebra was fully intact. Increased correction loss in the group 
Fig. 3 Boxplots showing kyphosis (Cobb angle) evolution during time for groups with one and two-segment anterior fixation. See also Table 6 for exact values. *Difference in Cobb angle increase from post-operative to final follow-up, the group with two segments maintains $4.7^{\circ}$ more kyphosis correction (corrected for different baseline post-operative values using multiple regression; $p<0.01$ )

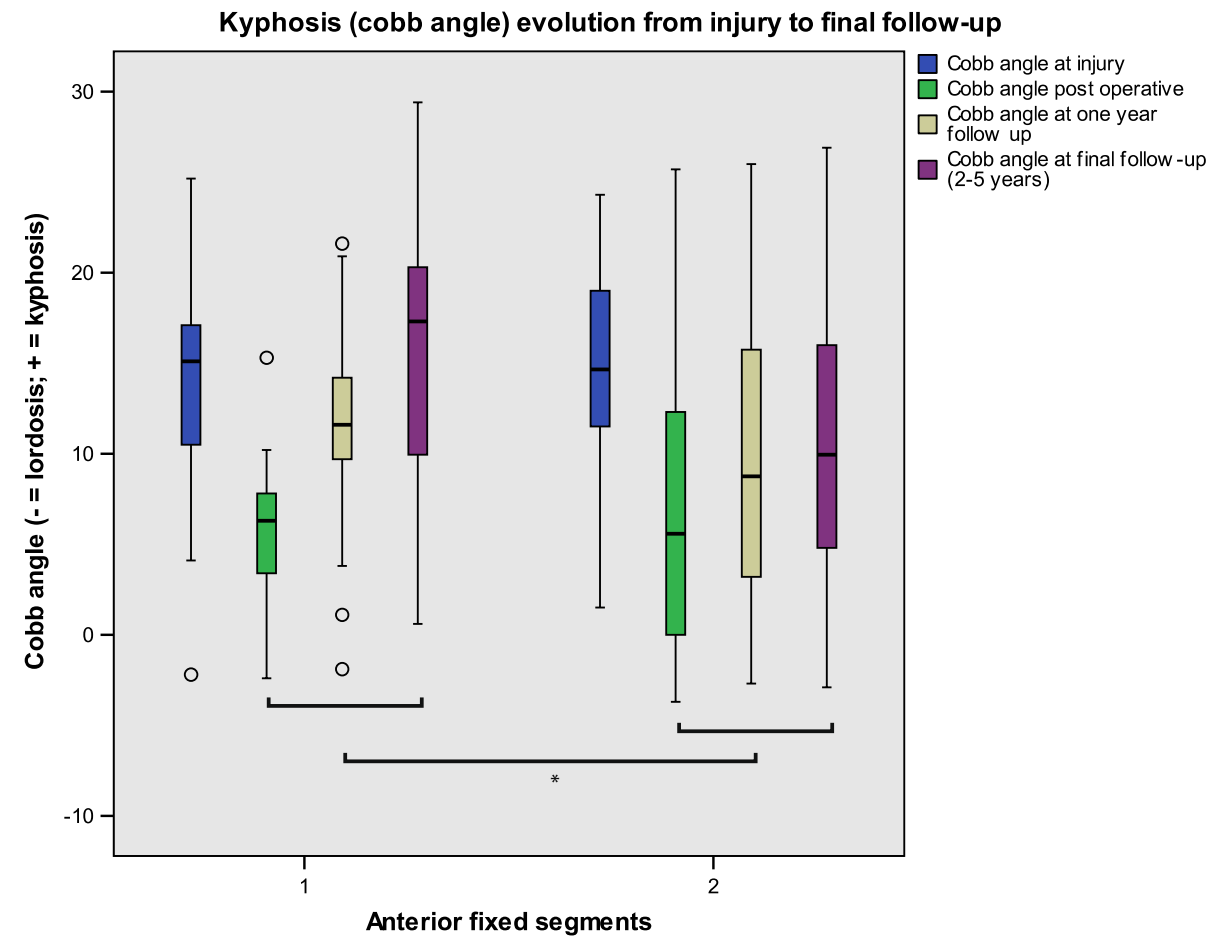

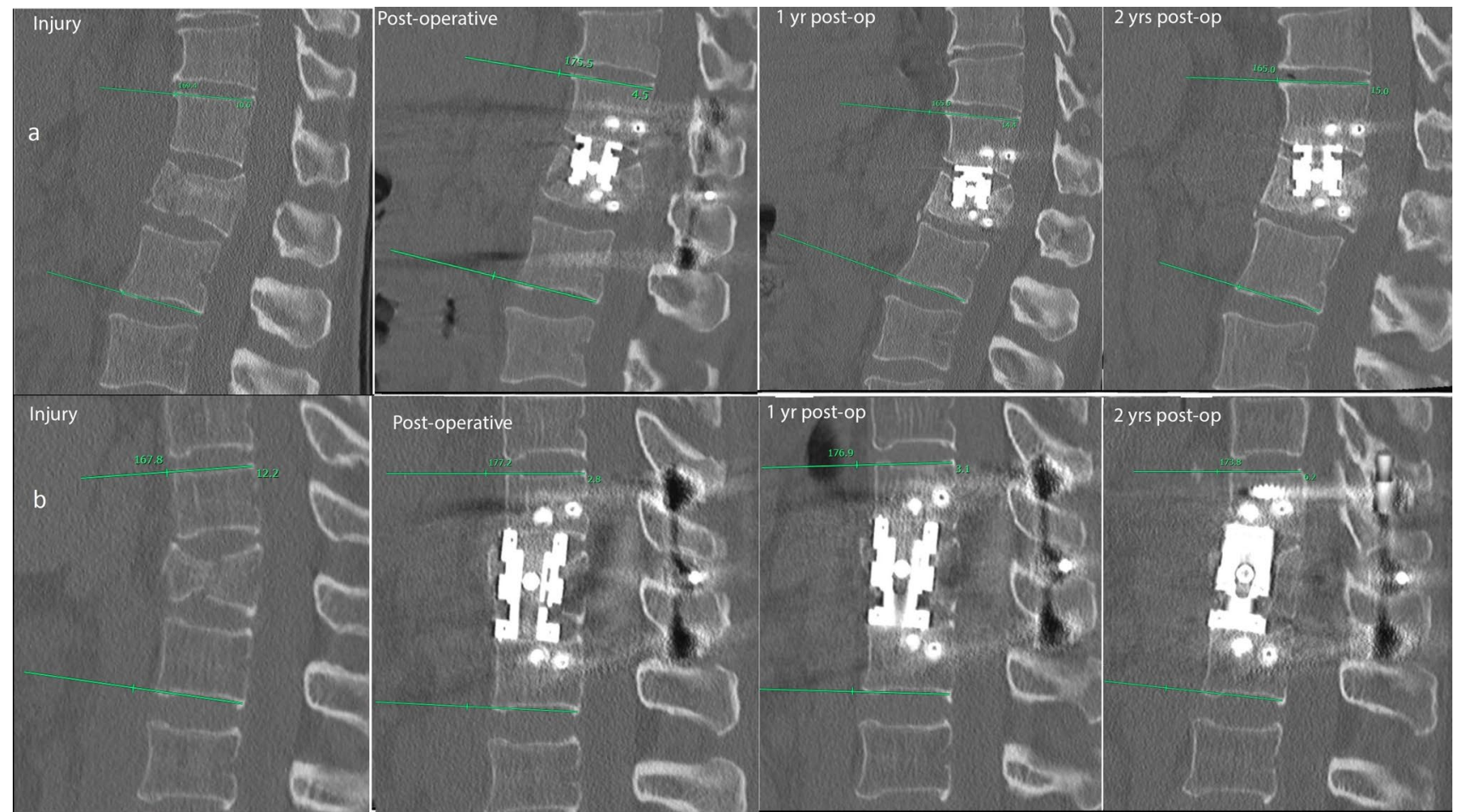

Fig. 4 Sagittal CT scan of two patients with, respectively, one (a) and two-segment (b) anterior fixation and difference in re-kyphosis at followup. Patient 2a underwent posterior implant removal

with one segment anterior fixation could be due to changes in the caudal intervertebral disc space, as has been reported before [1]. Furthermore, both groups show some correction loss, mainly in the first post-operative year (Table 6, Fig. 3), as in correspondence with the literature $[1,4]$. Posterior implant removal does not lead to major correction loss as 
Table 6 Change in kyphosis (Cobb angle) between one and two segment anterolateral plating at different moments (see also Fig. 3)

\begin{tabular}{lllll}
\hline Anterolateral plating & Moment 1 & Moment 2 & $\begin{array}{l}\text { Mean difference (kypho- } \\
\text { sis+, lordosis-) }\end{array}$ & (95\% CI) \\
\hline 1 anterior segment & CA injury & CA post-op & $-6.5^{* *}$ & $(-9.4$ to -3.6$)$ \\
& CA post OK & CA 1 year & $4.7^{* *}$ & $(2.6$ to 6.8) \\
& CA post-op & CA FFU & $9.3^{* *}$ & $(6.5$ to 12.1$)$ \\
& CA injury & CA FFU & 2.2 & $(-2.1$ to 6.5$)$ \\
2 anterior segments & CA injury & CA post-op & $-8.3^{* *}$ & $(-11.6$ to -5.1$)$ \\
& CA post OK & CA 1 year & $2.8^{* *}$ & $(1.5$ to 4.3$)$ \\
& CA post-op & CA FFU & $4.7^{* *}$ & $(2.4$ to 6.9$)$ \\
& CA injury & CA FFU & -3.6 & $(-7.4$ to 0.2$)$ \\
\hline
\end{tabular}

$C A$ Cobb angle, $F F U$ final follow-up, post-op post-operative

**Denotes a statistical difference from moment 1 to moment 2 with $p<0.01$ these are removed after approximately 1 year. It is likely that in this first year there is minimal cage subsidence while the construct 'settles down' $[4,7]$ before it becomes stable. Although we did not find a correlation between correction loss and QOL outcomes, we think that two segments anterior fixation is favorable to maintain more kyphosis correction.

Finally, it has to be noted that the emphasis of the surgical treatment of spine fractures is often on kyphosis correction. The main pillar of posterior stabilization combined with anterior stabilization, however, is to reconstruct the load bearing capacity of the anterior spine and, therefore, to prevent further vertebral body collapse and hardware failure $[1,6,35,36]$ in those cases with a high risk of collapse. The risk of collapse increases with intervertebral disc lesions [7] which cannot be sufficiently treated with only posterior fixation and often leads to non-union, pseudoarthrosis and vertebral collapse. We, therefore, strongly believe that without the anterior stabilization, the loss of correction would have been worse in our population.

\section{Technique characteristics}

The technique is technically demanding and operative time and blood loss depend partly on fracture- and patient characteristics. Surgeons wanting to take on this technique should prepare for long procedures with potential large blood loss, especially early in the learning curve. Operative time and blood loss decreased over time though, with the shortest procedure only ranging $108 \mathrm{~min}$ and $200 \mathrm{~mL}$ blood loss. The technique may provide large advantages but should only be used in centers that have sufficient exposure to severe fracture types. As the open approach is associated with large morbidity, we recommend that fractures indicated for anterior stabilization are treated at centers with thoracoscopic experience.

Compared to the conventional open approach, the thoracoscopic approach reduces surgical morbidity [13-15].
Another approach that might reduce surgical morbidity is the one stage posterior approach for both anterior and posterior stabilization [39-41]. A downside of this technically demanding approach is the high risk of accidental additional neurological damage, since the anterior column is approached from posterior. However, some authors reported only few complications and a high rate of neurological improvement. QOL after this approach, however, has not yet been reported and the question remains whether this approach is superior over the minimally invasive anterior thoracoscopic approach.

The next step in improving minimally invasive anteroposterior fixation using a thoracoscopic approach is the combination with percutaneous pedicle screw placement. This technique was not yet implemented at the time the included patients underwent surgery in our center. Furthermore, its results seem promising but still have to prove superiority on the long term $[42,43]$.

\section{Limitations}

The retrospective nature of this study brings inherent limitations such as missing and imprecise data and selection bias. While measuring kyphosis by Cobb angle has the best inter- and intraobserver precision [44], still relative large differences can be found between observers judging CT scan images. The patients in our population with an LSC $<7$ are possibly due to inter- and intraobserver variability of the LSC. Moderate inter- and intraobserver agreement of LSC scores between 3-6 and 7-9 has been reported [45]. Although results are stratified for injury severity, it is still possible that QOL is influenced by accompanying or even later sustained injuries. Furthermore, the patient sample is fairly small and stratification creates even smaller groups and thus introduces larger imprecision in outcomes. 


\section{Conclusion}

Thoracoscopic anterior stabilization with a distractible cage leads to a high percentage of bony fusion in unstable thoracic and thoracolumbar fractures, provides a stable construction over time and no hardware failure. Healthrelated QOL of these patients does not return to normal population values but is comparable to that of patients with less severe fractures treated with solely posterior instrumentation. The minimally invasive procedure is technically demanding, but safe with no re-interventions needed due to cage dislocation or implant failure and has a low complication rate. The use of a cage with two segments anterior fixation is preferable over one segment plating while this maintains more kyphosis correction on the long term.

\section{Compliance with ethical standards}

Conflict of interest All authors declare they have nothing to disclose that could potentially bias or influence this work.

Ethical approval This study was approved by the medical ethical committee METc VUmc with case number 2017.065.

Open Access This article is distributed under the terms of the Creative Commons Attribution 4.0 International License (http://creativeco mmons.org/licenses/by/4.0/), which permits unrestricted use, distribution, and reproduction in any medium, provided you give appropriate credit to the original author(s) and the source, provide a link to the Creative Commons license, and indicate if changes were made.

\section{References}

1. Knop C, Fabian HF, Bastian L, Blauth M (2001) Late results of thoracolumbar fractures after posterior instrumentation and transpedicular bone grafting. Spine (Phila Pa 1976) 26:88-99

2. Payer M (2006) Unstable burst fractures of the thoraco-lumbar junction: treatment by posterior bisegmental correction/fixation and staged anterior corpectomy and titanium cage implantation. Acta Neurochir 148:299-306. https://doi.org/10.1007/s0070 1-005-0681-5 (Discussion 306)

3. Reinhold M, Knop C, Beisse R, Audige L, Kandziora F, Pizanis A, Pranzl R, Gercek E, Schultheiss M, Weckbach A, Buhren V, Blauth M (2010) Operative treatment of 733 patients with acute thoracolumbar spinal injuries: comprehensive results from the second, prospective, Internet-based multicenter study of the Spine Study Group of the German Association of Trauma Surgery. Eur Spine J 19:1657-1676. https://doi.org/10.1007/s0058 6-010-1451-5

4. Schnake KJ, Stavridis SI, Kandziora F (2014) Five-year clinical and radiological results of combined anteroposterior stabilization of thoracolumbar fractures. J Neurosurg Spine 20:497-504. https ://doi.org/10.3171/2014.1.SPINE13246

5. Bakker FC, Segers MJM, Patka P, Haarman HJTM (2005) Operative treatment of thoracolumbar spine fractures. Osteo Trauma Care 13:208-213
6. Butt MF, Farooq M, Mir B, Dhar AS, Hussain A, Mumtaz M (2007) Management of unstable thoracolumbar spinal injuries by posterior short segment spinal fixation. Int Orthop 31:259264. https://doi.org/10.1007/s00264-006-0161-4

7. Graillon T, Farah K, Rakotozanany P, Blondel B, Adetchessi T, Dufour H, Fuentes S (2016) Anterior approach with expandable cage implantation in management of unstable thoracolumbar fractures: results of a series of 93 patients. Neurochirurgie 62:78-85. https://doi.org/10.1016/j.neuchi.2016.01.001

8. Verlaan JJ, Diekerhof CH, Buskens E, van der Tweel I, Verbout AJ, Dhert WJ, Oner FC (2004) Surgical treatment of traumatic fractures of the thoracic and lumbar spine: a systematic review of the literature on techniques, complications, and outcome. Spine (Phila Pa 1976) 29:803-814

9. Briem D, Rueger JM, Linhart W (2003) Osseous integration of autogenous bone grafts following combined dorso-ventral instrumentation of unstable thoracolumbar spine fractures. Unfallchirurg 106:195-203. https://doi.org/10.1007/s0011 3-002-0508-2

10. Kalra RR, Schmidt MH (2017) The role of a miniopen thoracoscopic-assisted approach in the management of burst fractures involving the thoracolumbar junction. Neurosurg Clin N Am 28:139-145. https://doi.org/10.1016/j.nec.2016.07.006

11. Lee CY, Wu MH, Li YY, Cheng CC, Lee CY, Huang TJ (2016) Video-assisted thoracoscopic surgery and minimal access spinal surgery compared in anterior thoracic or thoracolumbar junctional spinal reconstruction: a case-control study and review of the literature. Biomed Res Int 2016:6808507. https://doi. org/10.1155/2016/6808507

12. Pingel A, Castein J, Kandziora F (2017) Anterior monosegmental stabilization and fusion of an incomplete cranial burst fracture in the thoracolumbar spine via a mini-open, thoracoscopically assisted transthoracic approach. Eur Spine J 26:431-432. https:// doi.org/10.1007/s00586-017-5011-0

13. Khoo LT, Beisse R, Potulski M (2002) Thoracoscopic-assisted treatment of thoracic and lumbar fractures: a series of 371 consecutive cases. Neurosurgery 51:S104-S117

14. Kim DH, Jahng TA, Balabhadra RS, Potulski M, Beisse R (2004) Thoracoscopic transdiaphragmatic approach to thoracolumbar junction fractures. Spine J 4:317-328. https://doi.org/10.1016/j. spinee.2003.11.007

15. Shawky A, Al-Sabrout AM, El-Meshtawy M, Hasan KM, Boehm H (2013) Thoracoscopically assisted corpectomy and percutaneous transpedicular instrumentation in management of burst thoracic and thoracolumbar fractures. Eur Spine J 22:2211-2218. https://doi.org/10.1007/s00586-013-2835-0

16. Beisse R (2006) Endoscopic surgery on the thoracolumbar junction of the spine. Eur Spine J 15:687-704. https://doi.org/10.1007/ s00586-005-0994-3

17. Beisse R, Potulski M, Bühren V (2001) Anterior approaches for reconstruction of the spine following trauma. Reduction of morbidity by use of minimally invasive techniques. Trauma Berufskrankh 3(Suppl 3):S315-S320

18. Ray WZ, Krisht KM, Dailey AT, Schmidt MH (2013) Clinical outcomes of unstable thoracolumbar junction burst fractures: combined posterior short-segment correction followed by thoracoscopic corpectomy and fusion. Acta Neurochir 155:1179-1186. https://doi.org/10.1007/s00701-013-1737-6

19. Wood KB, Buttermann GR, Phukan R, Harrod CC, Mehbod A, Shannon B, Bono CM, Harris MB (2015) Operative compared with nonoperative treatment of a thoracolumbar burst fracture without neurological deficit: a prospective randomized study with follow-up at sixteen to twenty-two years. J Bone Joint Surg Am 97:3-9. https://doi.org/10.2106/JBJS.N.00226

20. Knop C, Kranabetter T, Reinhold M, Blauth M (2009) Combined posterior-anterior stabilisation of thoracolumbar injuries utilising 
a vertebral body replacing implant. Eur Spine J 18:949-963. https ://doi.org/10.1007/s00586-009-0970-4

21. McCormack T, Karaikovic E, Gaines RW (1994) The load sharing classification of spine fractures. Spine (Phila Pa 1976) 19:1741-1744

22. Aaronson NK, Muller M, Cohen PD, Essink-Bot ML, Fekkes M, Sanderman R, Sprangers MA, te Velde A, Verrips E (1998) Translation, validation, and norming of the Dutch language version of the SF-36 health survey in community and chronic disease populations. J Clin Epidemiol 51:1055-1068

23. Szende A, Janssen B, Cabases J (2014) Self-reported population health: an international perspective based on EQ-5D. Springer, Dordrecht

24. Smits AJ, Ouden LD, Jonkergouw A, Deunk J, Bloemers FW (2016) Posterior implant removal in patients with thoracolumbar spine fractures: long-term results. Eur Spine J. https://doi. org/10.1007/s00586-016-4883-8

25. Beisse R, Potulski M, Beger J, Buhren V (2002) Development and clinical application of a thoracoscopy implantable plate frame for treatment of thoracolumbar fractures and instabilities. Orthopade 31:413-422

26. Le Huec JC, Liu M, Skalli W, Josse L (2002) Lumbar lateral interbody cage with plate augmentation: in vitro biomechanical analysis. Eur Spine J 11:130-136. https://doi.org/10.1007/s0058 60100316

27. Schnake KJ, Stavridis SI, Krampe S, Kandziora F (2014) Additional anterior plating enhances fusion in anteroposteriorly stabilized thoracolumbar fractures. Injury 45:792-798. https://doi. org/10.1016/j.injury.2013.11.011

28. Velanovich V (2007) Behavior and analysis of 36-item short-form health survey data for surgical quality-of-life research. Arch Surg 142:473-477. https://doi.org/10.1001/archsurg.142.5.473 (Discussion 478)

29. Pfeifer R, Pishnamaz M, Dombroski D, Heussen N, Pape HC, Schmidt-Rohlfing B (2012) Outcome after thoracoscopic ventral stabilisation of thoracic and lumbar spine fractures. J Trauma Manag Outcomes 6:10. https://doi.org/10.1186/1752-2897-6-10

30. Thormann U, Erli HJ, Brugmann M, Szalay G, Schlewitz G, Pape HC, Schnettler R, Alt V (2013) Association of clinical parameters of operatively treated thoracolumbar fractures with quality of life parameters. Eur Spine J 22:2202-2210. https://doi.org/10.1007/ s00586-013-2799-0

31. Larsen P, Goethgen CB, Rasmussen S, Iyer AB, Elsoe R (2016) One-year development of QOL following orthopaedic polytrauma: a prospective observational cohort study of 53 patients. Arch Orthop Trauma Surg 136:1539-1546. https://doi.org/10.1007/ s00402-016-2550-5

32. Holtslag HR, van Beeck EF, Lindeman E, Leenen LP (2007) Determinants of long-term functional consequences after major trauma. J Trauma 62:919-927. https://doi.org/10.1097/01. ta.0000224124.47646.62

33. Zwingmann J, Hagelschuer P, Langenmair E, Bode G, Herget G, Sudkamp NP, Hammer T (2016) Lower health-related quality of life in polytrauma patients: long-term follow-up after over
5 years. Medicine 95:e3515. https://doi.org/10.1097/MD.00000 00000003515

34. Briem D, Linhart W, Lehmann W, Bullinger M, Schoder V, Meenen NM, Windolf J, Rueger JM (2003) Investigation of the health-related quality of life after a dorso ventral stabilization of the thoracolumbar junction. Unfallchirurg 106:625-632. https:// doi.org/10.1007/s00113-003-0627-4

35. McLain RF, Sparling E, Benson DR (1993) Early failure of shortsegment pedicle instrumentation for thoracolumbar fractures. A preliminary report. J Bone Joint Surg Am 75:162-167

36. Alanay A, Acaroglu E, Yazici M, Oznur A, Surat A (2001) Shortsegment pedicle instrumentation of thoracolumbar burst fractures: does transpedicular intracorporeal grafting prevent early failure? Spine (Phila Pa 1976) 26:213-217

37. Schulz R, Melcher RP, Garib MC, Schulz H, Weissman K, Harms J (2014) Does kyphotic deformity correlate with functional outcomes in fractures at the thoracolumbar junction treated by 360 degrees instrumented fusion? Eur J Orthop Surg Traumatol 24(Suppl 1):S93-S101. https://doi.org/10.1007/s0059 0-014-1435-y

38. Gertzbein SD (1992) Scoliosis Research Society. Multicenter spine fracture study. Spine (Phila Pa 1976) 17:528-540

39. Lai O, Hu Y, Yuan Z, Sun X, Dong W, Zhang J, Zhu B (2016) Modified one-stage posterior/anterior combined surgery with posterior pedicle instrumentation and anterior monosegmental reconstruction for unstable Denis type B thoracolumbar burst fracture. Eur Spine J. https://doi.org/10.1007/s00586-016-4800-1

40. Zheng GQ, Wang Y, Tang PF, Zhang YG, Zhang XS, Guo YZ, Tao S (2013) Early posterior spinal canal decompression and circumferential reconstruction of rotationally unstable thoracolumbar burst fractures with neurological deficit. Chin Med J 126:2343-2347

41. Hunt T, Shen FH, Arlet V (2006) Expandable cage placement via a posterolateral approach in lumbar spine reconstructions. Technical note. J Neurosurg Spine 5:271-274. https://doi.org/10.3171/ spi.2006.5.3.271

42. McAnany SJ, Overley SC, Kim JS, Baird EO, Qureshi SA, Anderson PA (2016) Open versus minimally invasive fixation techniques for thoracolumbar trauma: a meta-analysis. Glob. Spine J 6:186194. https://doi.org/10.1055/s-0035-1554777

43. Phan K, Rao PJ, Mobbs RJ (2015) Percutaneous versus open pedicle screw fixation for treatment of thoracolumbar fractures: systematic review and meta-analysis of comparative studies. Clin Neurol Neurosurg 135:85-92. https://doi.org/10.1016/j.cline uro.2015.05.016

44. Kuklo TR, Polly DW, Owens BD, Zeidman SM, Chang AS, Klemme WR (2001) Measurement of thoracic and lumbar fracture kyphosis: evaluation of intraobserver, interobserver, and technique variability. Spine (Phila Pa 1976) 26:61-65 (Discussion 66)

45. Elzinga M, Segers M, Siebenga J, Heilbron E, de Lange-de Klerk ES, Bakker F (2012) Inter- and intraobserver agreement on the load sharing classification of thoracolumbar spine fractures. Injury 43:416-422. https://doi.org/10.1016/j.injury.2011.05.013

\section{Affiliations}

\section{Arjen J. Smits ${ }^{1}\left(\mathbb{D} \cdot\right.$ Arwin Noor $^{1} \cdot$ Fred C. Bakker $^{1} \cdot$ Jaap Deunk ${ }^{1} \cdot$ Frank W. Bloemers $^{1}$}

Arjen J. Smits

aj.smits@vumc.nl
1 Department of Trauma Surgery, VU University Medical Centre, De Boelelaan 1117, 1081 HV Amsterdam, The Netherlands 